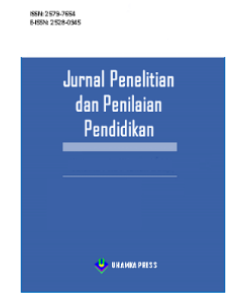

Jurnal Penelitian dan Penilaian Pendidikan

ISSN:2579-7654 (Online) 2528-0945 (Print)

Journal Homepage: https://journal.uhamka.ac.id/index.php/jppp

\title{
EVALUASI RELEVANSI KEILMUAN DAN DUNIA KERJA MAHASISWA PASCASARJANA UHAMKA
}

\section{Ernawati | Sri Yuliawati | Puji Hartini}

How to cite : Ernawati, Yuliawati, Sri., \& Hartini, Puji., 2021. EVALUASI RELEVANSI KEILMUAN DAN DUNIA KERJA MAHASISWA PASCASARJANA UHAMKA. Jurnal Penelitian dan Penilaian Pendidikan. 3(1). 92-101.

To link to this article : https://doi.org/10.22236/jppp.v3i1.6299

(C2021. The Author(s). This open access article is distributed under a Creative Commons Attribution (CC BY-SA) 4.0 license.

Published Online on 12 January 2021

View Crossmark data $₫$ 
EVALUASI RELEVANSI KEILMUAN DAN DUNIA KERJA MAHASISWA PASCASARJANA UHAMKA

\author{
Ernawati $^{1}$, Sri Yuliawati ${ }^{2}$, Puji Hartini ${ }^{3} \bowtie$ \\ 1,2,3 Universitas Muhammadiyah Prof DR HAMKA \\ E-mail: $\quad$ ernawati@uhamka.ac.id ${ }^{1)}$ \\ sri.yuliawati@uhamka.ac.id ${ }^{2)}$ \\ puji.hartini@uhamka.ac.id ${ }^{3 *}$
}

Received: 12 November 2020, Accepted: 1 Desember 2020, Published Online: 12 Januari 2021

\begin{abstract}
Abstrak
Penelitian ini dilatarbelakangi oleh kepentingan evaluasi hasil pendidikan tinggi, perbaikan mutu dan penjaminan kualitas lembaga pendidikan tinggi dari alumni yang merupakan produk akhir dari proses pembelajaran. Tujuan penelitian ini adalah untuk menganalisis kompetensi kerja dan ruang lingkupkerja alumni. Penelitian ini menggunakan metode deskriptif kuantitatif dengan menggunakan survey. Adapun hasil penelitian ini menunjukkan 26\% alumni yang menjadi subyek tracer menyatakan sedang kesesuaian antara bisang studi yang dipelajari dengan bidang pekerjaan yang ditekuninya saat ini dan mayoritas alumni bekerja pada institusi pemerintah.
\end{abstract}

Kata kunci: Tracer Study Alumni, Kompetensi Kinerja, Ruang Lingkup Kerja

\begin{abstract}
This research is motivated by the importance of evaluating the results of higher education, quality improvement and quality assurance of higher education institutions from alumni which is the end product of the learning process. The purpose of this research is to analyze the work competence and work scope of alumni. This study uses a quantitative descriptive method using a survey. The results of this study showed that $26 \%$ of alumni who were tracer subjects stated that there was a good match between the subject being studied and the field of work they are currently practicing and the majority of alumni work in government institutions.
\end{abstract}

Keywords: Alumni Tracer Study, Performance Competency, Scope of Work

This is an open access article under the Creative Commons Attribution 4.0 International License 


\section{PENDAHULUAN}

Lulusan atau alumni merupakan produk akhir dari sebuah proses yang ada di suatu perguruan tinggi. Salah satu penilaian yang dilakukan oleh masyarakat terhadap kualitas perguruan tinggi adalah dengan melihat reputasi alumninya di tengah masyarakat ataupun di dunia kerja. Berbagai kiprah alumni yang berhasil di dalam karirnya, akan berdampak positif terhadap peningkatan reputasi UHAMKA di mata masyarakat. Tracer study merupakan studi penelusuran yang dilakukan kepada lulusan perguruan tinggi dalam rangka mendapatkan umpan balik dari lulusan untuk kepentingan evaluasi hasil pendidikan tinggi dan juga perbaikan mutu dan penjaminan kualitas lembaga pendidikan tinggi. Setiap institusi harus selalu berupaya melakukan perbaikan sistem dan peningkatan kualitas. Salah satu cara untuk meningkatkan kualitastersebut adalah dengan mencari umpan balik dari alumni melalui kegiatan Tracer study.

Universitas Muhammadiyah Prof. DR. HAMKA dalam perjalananannya sudah banyak menghasilkan lulusan. Sebaran lulusan ini dapat diketahui melalui kegiatan tracer study.Kegiatan tracer yang dilakukan oleh UHAMKA tahun ini merupakan kegiatan yang ketiga. Hasil dari pelaksanaan tracer study yang dilakukan oleh UHAMKA pada tahun 2019, angka partisipasi alumni (response rate) dinilai masih belum signifikan, pada lulusan tahun 2016 angka partisipasi $15 \%$. Kemudian pada lulusan tahun 2017 angka partisipasi 21\%. Kemudian pada lulusan tahun 2018 angka partisipasi 25\%. Rendahnya angka partisipasi ini perlu disiasati agar UHAMKA mendapatkan feedback yang optimal dari alumni. Tingkat respon yang dianggap layak dalam pelaksanaan tracer study diangka 50\%, hal ini menggambarkan setengah dari karakteristik dan profil responden.

Penelitian terdahulu terkait tracer study telah banyak dilakukan yang berfungsi sebagai bahan analisa dan memperkaya pembahasan penelitian ini, serta sebagai pembeda dengan penelitian yang akan dilakukan. Penelitian yang dilakukan oleh Zulhimma (2015); Evi Roviati, dkk (2015); Muhammad Ilham Bakhtiar dan Suciani Latif pada (2017); Maryam Rahim dan Meiske Puluhulawa (2017) menggunakan deskriptif persentase dalam menganalisis data tracer study. Selanjutnya, Ramadiani, dkk(2016) melakukan penelitian yang bertujuan untuk melakukan analisis perancangankebutuhan sistem tracer study Universitas Mulawarman yang disesuaikan dengan kebutuhan informasi dalam proses akreditasi.

\section{Ernawati}

ernawati.pep@uhamka.ac.id

1 Program Studi Penelitian Evaluasi Pendidikan, Universitas Muhammadiyah Prof. DR.

HAMKA, Jakarta, Indonesia 
Hasil penelitian ini menunjukkan bahwa sistem memiliki manfaat berikut: 1) memenuhi kebutuhan data dan informasi terkait lulusan; 2) memenuhi kebutuhan data akreditasi perguruan tinggi; 3) mempermudah perguruan tinggi dalam mengelola data lulusan; dan 4) memudahkan perguruan tinggi dalam menunjang keputusan menentukan perencanaan strategis sebagai upaya peningkatan kualitas mutu lulusan.

Miftahul Khair, dkk (2016) melakukan penelitian berjudul Alumni Tracer System Berbasis Web: Studi Kasus Fakultas Matematika dan Ilmu Pengetahuan Alam. Penelitian ini bertujuan untuk membuat suatu rancangan sistem berbasis web yang dapat digunakan untuk mendata informasi dari alumni. Hasil penelitian ini menunjukkan bahwa: 1) Sistem dapat merekam data dengan menggunakan basis data sehingga data alumni tersimpan secara terstruktur; 2) sistem berjalan sesuai yang diharapkan oleh penulis; 3) pemanfaatan website dapat berfungsi sebagai media survey, dan melalui website secara online kegiatan survey dapat dilakukan dengan efektif dan efisien.

Budi Santoso, dkk (2019) melakukan penelitian yang berjudul Studi Pelacakan Kinerja Lulusan Program Pascasarjana Magister Ilmu Ekonomi (MIE) Fakultas Ekonomi dan Bisnis Universitas Mataram. Penelitian bertujuan untuk mengkaji: a) kondisi Proses belajar mengajar dan manajemen internal di Prodi MIE UNRAM; b) kebutuhan soft dan hard skills lulusan/ alumni Prodi MIE UNRAM; dan c) penilaian pengguna terhadap kinerja lulusan Prodi MIE UNRAM. Data diperoleh dengan wawancara. Hasil penelitian menunjukan bahwa Alumni menyatakan pentingnya pengalaman magang, penekanan besar terhadap aspek peragaan atau demontrasi materi perkuliahan, dan pembimbingan akademik bernilai besar dalam proses pembelajaran. Sedangkan soft dan hard skills yang mereka butuhkan adalah kemampuan mengkomunikasikan hasil penelitian, dan gagasan mereka dengan dunia praktik.

Tracer study ini akan mengkaji profil responden, penilaian alumni terhadap kinerja UHAMKA, serapan dunia kerja bagi alumni, kondisi pekerjaan alumni, dan penilaian alumni terhadap kegiatan Al-Islam Kemuhammadiyahan (AIK) di UHAMKA. Sistem yang akan digunakan dalam Tracer study ini adalah sistem tracer study uhamka yang telah dikembangkan sejak tahun 2017. Selanjutnya, peneliti akan memodifikasi sistem agar dapat diakses dengan mudah oleh para alumni, serta dibantu dengan aplikasi lain seperti Google form. Selanjutnya, data Tracer study akan dianalisis dengan mixed method. 
Studi pelacakan jejak alumni atau survey lulusan atau Tracer study telah dijadikan sebagai salah satu dimensi akreditasi perguruan tinggi dan berbagai program hibah kompetisi yang diselenggarakan oleh Kementrian Ristek dan Dikti akhir akhir ini.Tracer study menjadi semakin penting perannya karena dapat memberikan berbagai informasi utama untuk pengembangan perguruan tinggi yang melaksanakan Tracer study tersebut. Data dan Informasi yang diperoleh melalui Tracer study, berperan sebagai alat untuk mengevaluasi relevansi antara pendidikan tinggi dengan pasaran dan kebutuhan dunia kerja, menyajikan berbagai masukan yang berguna bagi dosen dan administrator untuk peningkatan kinerja layanan pendidikan, serta masukan bagi para orangtua dalam memantau layanan pendidikan di perguruan tinggi untuk anaknya (Sukardi, 2010).

Pelaksanaan Tracer study di Perguruan Tinggi, tidak lain juga disebabkan karena perguruan tinggi membutuhkan umpan balik dari alumni dalam usahanya untuk perbaikan sistem dan pengelolaan pendidikan. Perencanaan program kerja perguruan tinggi di awal tahun ajaran menentukan arah kebijakan layanan pendidikan tinggi tahun berjalan dan selanjutnya, berupa penyiapan kondisi, proses pemberian pengalaman melalui pembelajaran, dan motivasi mahasiswa baru yang masuk ke perguruan tinggi tersebut dengan berbagai harapan yang telah diimpikan. Masukkan mengenai kondisi, pengalaman dan motivasi ini menentukan pula perguruan tinggi dalam menerapkan sistem dan pengelolaan pendidikan dalam hal pola/proses pengajaran dan pembelajaran,penelitian, praktikum, workshop, laboratorium, studio ataupun riset. Penerapan sistem pengajaran dan pembelajaran inipun akan dipengaruhi pula oleh kebijakan pendidikan yang ditetapkan oleh perguruan tinggi.

Hasil Tracer study menjadi masukkan bagi perguruan tinggi berupa keadaan nyata, pengalaman dan motivasi yang diberikan kepada mahasiswa, sistem dan kebijakan pendidikan di perguruan tinggi, berikut proses pengajaran/ pembelajaran yang akan membantu dalam membentuk karakter/kompetensi dari lulusan perguruan tinggi itu sendiri. Lulusan/alumni dari perguruan tinggi umumnya akan memiliki pengetahuan, kemampuan, motivasi dan kompetensi yang dibutuhkan untuk memasuki dunia kerja hasil dari proses layanan pembelajaran di pendidikan tinggi berupa pengetahuan, kemampuan dan kompetensi alumni perguruan tinggi yang dibutuhkan untuk memasuki dunia kerja. Kondisi saat alumni menjalani pekerjaan di awal karir mereka merupakan hal yang dibutuhkan bagi perguruan tinggi untuk perbaikan sistem dan pengelolaan pendidikan. 
Penelitian ini bertujuan untuk menganalisis tingkat kepuasan pengguna lulusan terkait dengan kemampuan melaksanakan tugas profesional alumni UHAMKA di tempat kerja dengan beberapa dimensi sebagai berikut, etika bekerja dan beinteraksi di kantor, kompetensi utama yang dimiliki dengan bidang tugas dan tanggung jawabnya, kemampuan berbahasa asing, ketrampilan IT, ketrampilan berkomunikasi bisnis, kerjasama tim dan upaya pengembangan diri. Hal sangat penting dalam pengembangan jaringan kerja UHAMKA dengan stake holder.

\section{METODE PENELITIAN}

Pada dasarnya ada empat tahapan utama dalam pelaksanaan Tracer study, yaitu mulai dari pengembangan konsep dan instrumen, dilanjutkan dengan pengumpulan data,kemudian analisis data yang sudah terkumpul, dan terakhir adalah penyusunan laporan hasil Tracer study. Pada tahap pertama, dilakukan pengembangan konsep dan instrumenkuesioner Tracer study yang terdiri dari sejumlah item pertanyaan yang sesuai dengan standar BELMAWA KEMENRISTEKDIKTI dan ditambahkan dengan item-item yang disesuaikan dengan kebutuhan UHAMKA. Sebelum disebar kuisioner melalui tahapan verifikasi terlebih dahulu. Tahap kedua, dilanjutkan dengan proses penggalian umpan balik dari para responden yang dilakukan secara daring/online agar dapat memudahkan responden dalam mengisi, sekaligus sebagai upaya untuk meningkatkan response rate.

\section{HASIL PENELITIAN DAN PEMBAHASAN}

\section{Hasil Penelitian 1}

Kesesuaian antara komptensi dan pengetahuan yang dimiliki dengan bidang kerja yang ditekuni pada saat ini menjadi suatu kewajaran bagi setiap pekerja pada perusahaan atau dalam kontek guru dengan bidang studi dan kelas yang diajar.

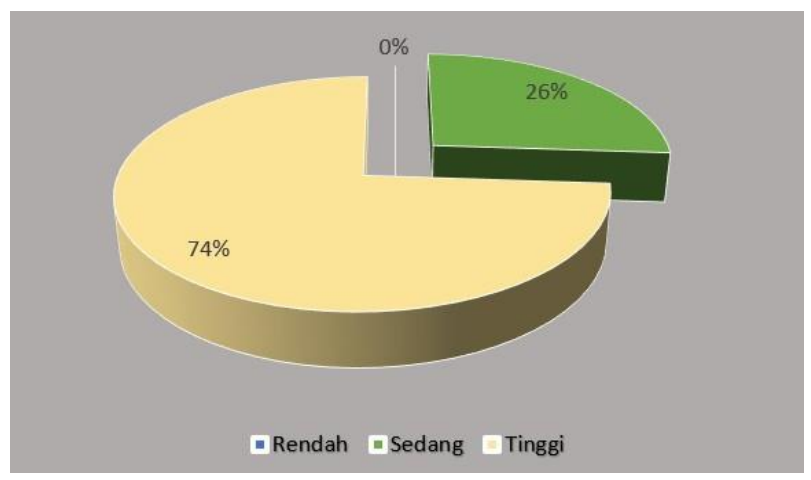

Grafik 1 Kesesuaian Bidang Studi dengan Pekerjaan 
Terdapat $26 \%$ alumni yang menjadi subyek tracer menyatakan sedang kesesuaian antara bisang studi yang dipelajari dengan bidang pekerjaan yangditekuninya saat ini. Tidak ada alumni yang menyatakan tidak ada kesesuian. Hasil tracer study ini menunjukkan ketiga ranah menunjukkan pada intensitas yang sama. Dengan adanya kecenderungan ini interpetasi terhadap fenomena ini adalah bahwaketiga ranah ini mendapat porsi yang sama ketika alumni mengukiti program pendidikan di SPS UHAMKA Prodi PEP. Jika hal ini memberikan dampak pada alumniketika mereka sudah lulus dan menjalani kehidupan profesional dalam berbagai bidang pekerjaan maka program pendidikan ini perlu untuk dipertahankan.

Kecenderungan empirik yang ditunjukkan pada grafik tersebut juga didukung oleh kecenderungan empirik yang disajikan menunjukan $74 \%$ alumni yang menjadi subyek tracer study ini menyatakan bahwa bidang studi yang dijalaninya sesuai dengan bidang pekerjaan yang dijalaninya saat ini. Pernyataan bidang studi paling tidak termasuk bidang studi yang dipelajarinya pada SPS UHSMKS Prodi PEP, dan ada kemungkinan termasuk bidang studi ketika alumni mengikuti program studi pada strata 1 atau strata 2 pada bidang lain.

\section{Hasil Penelitian 2}

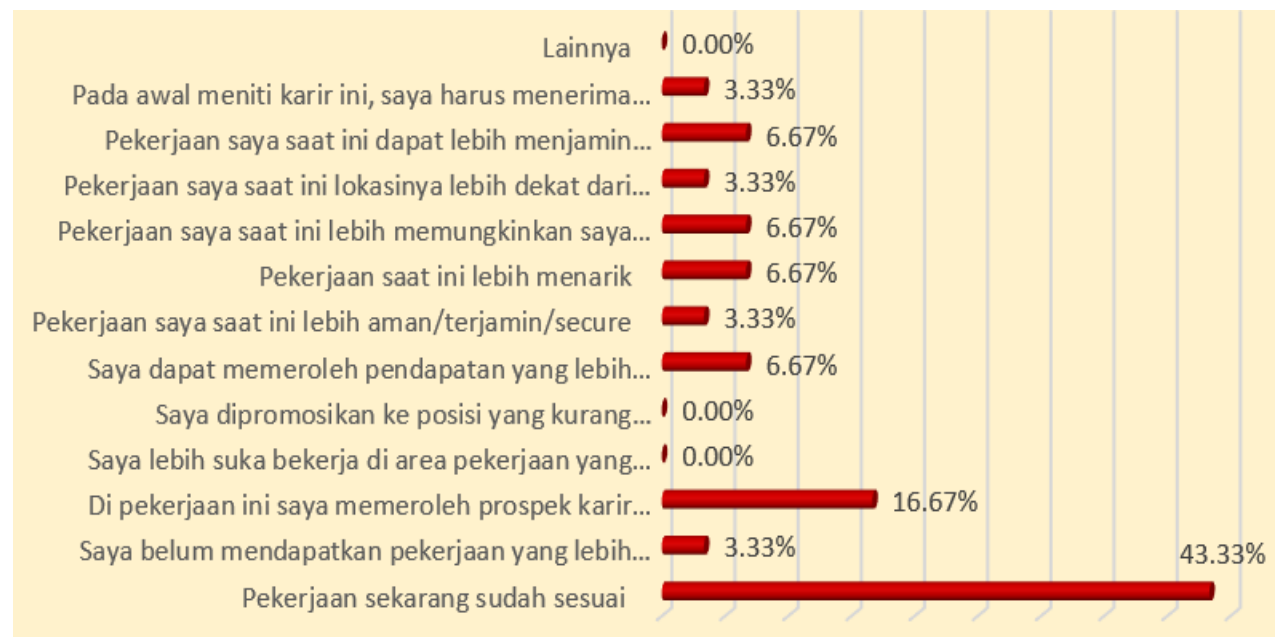

Grafik 2 Kesesuaian Pekerjaan dan Alasan Tetap Mengambil Pekerjaan Meskipun Belum Tidak Sesuai Dengan Bidang Pendidikan

Dengan adanya kesuaian kmpotensi yang dimilki dengan bidang pekerjaan yang ditekuni pada saat ini menjadi dorongan bagi alumni untuk tetap menekuni pekerjaan yang telah ditekuni pada saat ini. Grafik ..... 
berikut menyajika fakta empirik yakni $43 \%$ alumni tetap pada pekerjaan yang ditekuni saat ini karena dianggap sudah sesuai. Kata sudah sesuai mempunyai makna kesesuain antara kompetensi dan pengetahuan yang dimilik dengan persyaratan pekerjaan yang ditekuni saat ini. Kecenderungan empirik inimendukung terhadap kecenderungan empirik yang disajikan pada grafik di atas.

Prospek karir pada pekerjaan yang ditekuni alumni menjadi alasan yang dominan bagi alumni untuk menekuni pekerjaannya saat ini (16\%). Demikian juga dengan sekitar6\% alumni juga menyatakan bahwa pekerjaan yang ditekuni saat ini menjamin. Namun kata menjamin tidak ada indikasi apa, namun dapat diduga kata menjamin keberlangsung pekerjaan, penghasilan yang diperoleh, dan rekan kerja yang saling mendukung satu dengan lainnya. Jaminan kerja menjadi alasan bagi alasan sekitar 3\% alumni untuk tetap menekuni pada pekerjaan sekarang. Kata lebih aman dapat juga mencakup penghasilan atau dukungan teman sejawat. Dengan adanya 6,67\% alumni yang menyatakan bahwa pekerjaan yang sekarang alumni memperoleh penghasilanyang lebih.

Namun ada sebagian kecil $(3,33 \%)$ alumni yang akan mencari pekerjaan pada tempat lain di masa depan. Hal ini terungkap dari jawabannya yang menyatakan pada awal meniti karir saya harus menerima. Secara implisit hal ini berarti jika ada kesempatan tawaran pekerjaan yang lebih propreksi tidak menutup kemungkinan alumni tersebut akan pindah bidang pekerjaan.

\section{Hasil Penelitian 3}

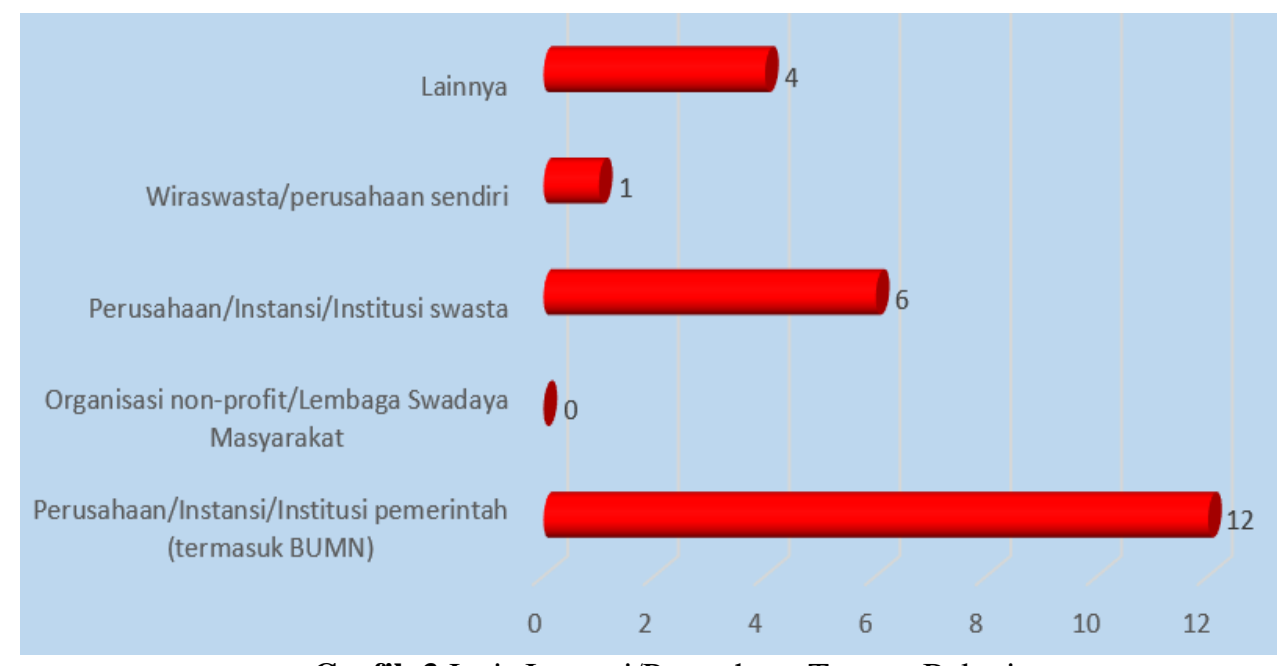

Grafik 3 Jenis Instansi/Perusahaan Tempat Bekerja 
Pada grafik 3 di atas juga ditunjukkan bahwa terdapat alumni yang berwiraswasta sendiri meskipun pada porsi yang sangat kecil, namun hal ini dapat menjadi indikasi kemandirian alumni. Mereka yang memberikan les privat kepada siswa dapat juga dikategorikan sebagai wiraswasta mandiri, namun bagi mereka yang bergerak di bidang perdagangan juga dapat dikategorikan sebagai wiraswasta mandiri. Bagi masyarakat pada umumnya wirawasta dalam bidang perdagangan merupakan bentuk wiraswasta yang dianggap populer dan dikenal secara luas.

Hasil tracer study menyajikan suatu kecenderungan yang bersifat dan berdampak positif terhadap SPS UHAMKA Prodi PEP dan bagi alumni itu sendiri. Jikan dilakukan inferensi terhadap kecenderungan tersebut dapat dikembangkan menjadi dua konsep yaitu knowledge development dan intelectual integrity.

Inferensi terhadap knowledge development adalah dengan mengikuti kuliah di SPS UHAMKA Prodi PEP alumni mendapat bekal pengetahuan dan kompetensi yang mendukung pada kehidupan profesional mereka. Sumbangan terhadap kehidupan profesional dalam berbagai bidang dimulai ketika alumi mencari pekerjaan sampai dengan berkarir pada pekerjaan yang ditekuninya sekarang.

Ketika pengetahuan dan kompetensi ini memberikan sumbangan terhadap kehidupan profesional alumni akan menstimulai alumni untuk mengembangkan pengetahuan dan komptensi yang telah dimilikinya menjadi akses untuk menjelajah berbagai dimensi kehidupan profesional alumni. Dengan adanya kemampuan untukmenjelajah berbagai dimensi kehidupan, maka hal ini akan memberikan dampak positif tidak hanya terdap dirinya tetapi terhadap instansi dan atau tempat mereka bekerja baik mereka yang berkerja pada skala multi nasional atau nasional, atau mereka yang bekerjapada organisasi swasta atau instansi pemerintah, atau bahkan bagi alumni yang melakukan wiraswasta. Jika dilihat dari perspektif pedagogi knowled developmen ini dapat juga mempeberikan dampak positif afektif bagi diri alumni dan individu sekitar alumni. Hal ini akan mengokohkan pengetahuan dan komptensi yang dimiliki oleh alumni.

Intelectual integrity merupakan hasil keikutsertaan alumni pada proses belajar mengajar pada pendidikan yang berlangsung di SPS UHAMKA Prodi PEP. Salah satu indikator yang menonjol adalah adanya intelectual enggagement. Intelectual enggagement merupakan karakterisitk intelektual yang melekat pada diri alumni ketika mereka sudah memasuki bidang profesional. Karakteristik intelektual ini tidak hanya melekat pada 
diri alumni tetapi pada SPS UHAMKA Prodi PEP. Dalam jangka panjang jika karakteristik intelektual sebagai wujud intelectual integrity melekat pada alumnidan SPS UHAMKA Prodi PEP maka akan menjadi mazhab akademik.

Pada perguruan tinggi di negara-negara barah mazhab menjadi ciri khas akademik perguruan tinggi yang secara berkelanjutan dilakukan pembuktian secara empirik. Mazhab ilmu pengetahuan ini nilai jual bagi perguruan bagi calon mahasiswa dan bagi berbagai instansi untuk melakukan kerjasama.

\section{KESIMPULAN}

Berdasarkan pembahasan di atas dapat disimpulkan bahwa: terdapat 26\% alumni yang menjadi subyek tracer menyatakan sedang kesesuaian antara bisang studi yang dipelajari dengan bidang pekerjaan yang ditekuninya saat ini dan tidak ada alumni yang menyatakan tidak ada kesesuian. Mayoritas alumni, sekitar 70\% memnyatakan bahwa komptensi pengajaran pada SPS UHAMKA Prodi PEP mempunyai pengaruh kuat dalam memberikan bekal kepadaalumni dalam mencari pekerjaan dan atau mengembangkan karir setelah mereka lulus.

\section{DAFTAR PUSTAKA}

Bakhtiar, M. I., dan Latif, S. (2017). Tracer Study Alumni: Upaya Pengembangan Prodi Bimbingan Konseling Universitas Negeri Makassar. Jurnal Kajian Bimbingan dan Konseling, 2(1), 32-40.

Budi, Bambang Setia. (2017). Report Tracer study ITB 2018. ITB Career Center Lembaga Kemahasiswaan. ITB Press.

Budi Santoso, dkk. (2019). Studi Pelacakan Kinerja Lulusan Program Pascasarjana Magister Ilmu Ekonomi (MIE) Fakultas Ekonomi Dan Bisnis Universitas Mataram. Elastisitas - Jurnal Ekonomi Pembangunan, 1(1), 1-15.

Khair, M, dkk. (2016). Alumni Tracer System Berbasis Web: Studi Kasus Fakultas Matematika Dan Ilmu Pengetahuan Alam. Prosiding Seminar Sains dan Teknologi FMIPA Unmul.

Panduan Hibah Tracer study (2016). Direktorat Jendral Pembelajaran dan kemahasiswaan Kementrian Riset dan Teknologi Republik Indonesia.

Rahim, M dan Puluhulawa, M. (2017). Tracer Study Lulusan Program Studi Bimbingan Dan Konseling Universitas Negeri Gorontalo. Jurnal Pendidikan (Teori dan Praktik), 2(2), 121-127.

Ramadiani, dkk. (2016). Tracer Study Menggunakan Framework Bootstrap. Prosiding Seminar Ilmu Komputer dan Teknologi Informasi, 1(1), 1-7.

Roviati, E., dkk. (2015). Tracer Study: Studi Rekam Jejak Alumni dan Respons Stakeholder Jurusan Tadris IPA-Biologi Iain Syekh Nurjati Cirebon. ScientiaeEducatia, 5(1).

Schomburg, H., (2009). Diversity and Benefits of Tracer Studies. Jakarta.

Sukardi, Thomas. (2010). "Studi Penelusuran Lulusan S1 Kependidikan Fakultas 
Teknik Universitas Negeri Yogyakarta.

Zulhimma. (2015). Tracer Study Alumni Dalam Meningkatkan Mutu Akademik Di

Fakultas Tarbiyah dan Ilmu Keguruan Iain Padangsidimpuan. Jurnal Tazkir, 1(2), 92-107. 